\title{
Low serum albumin and total lymphocyte count as predictors of 30 day hospital readmission in patients 65 years of age or older
}

Robert Robinson

Introduction: Hospital readmission within 30 days of discharge is a target for health care cost savings through the medicare Value Based Purchasing initiative. Because of this focus, hospitals and health systems are investing considerable resources into the identification of patients at risk of hospital readmission and designing interventions to reduce the rate of hospital readmission. Malnutrition is a known risk factor for hospital readmission.

Materials and Methods: All medical patients 65 years of age or older discharged from Memorial Medical Center from January 1, 2012 to March 31, 2012 who had a determination of serum albumin level and total lymphocyte count on hospital admission were studied retrospectively. Admission serum albumin levels and total lymphocyte counts were used to classify the nutritional status of all patients in the study. Patients with a serum albumin less than $3.5 \mathrm{grams} / \mathrm{dL}$ and/or a TLC less than 1,500 cells per $\mathrm{mm} 3$ were classified as having protein energy malnutrition. The primary outcome investigated in this study was hospital readmission for any reason within 30 days of discharge.

Results: The study population included 1,683 hospital discharges with an average age of 79 years. The majority of the patients were female (55.9\%) and had a DRG weight of 1.22 (0.68). 219 patients (13\%) were readmitted within 30 days of hospital discharge. Protein energy malnutrition was common in this population. Low albumin was found in 973 (58\%) patients and a low TLC was found in 1,152 (68\%) patients. Low albumin and low TLC was found in 709 (42\%) of patients. Kaplan-Meier analysis shows any laboratory evidence of PEM is a significant $(p<0.001)$ predictor of hospital readmission. Low serum albumin $(p<$ $0.001)$ and TLC ( $p=0.018)$ show similar trends. Cox proportional-hazards regression analysis showed low serum albumin (Hazard Ratio 3.27, 95\% Cl: 2.30-4.63) and higher DRG weight (Hazard Ratio 1.19, 95\% Cl: 1.03-1.38) to be significant independent predictors of hospital readmission within 30 days.

Discussion: This study investigated the relationship of PEM to the rate of hospital readmission within 30 days of discharge in patients 65 years of age or older. These results indicate that laboratory markers of PEM can identify patients at risk of hospital 
readmission within 30 days of discharge. This risk determination is simple and identifies a potentially modifiable risk factor for readmission: protein energy malnutrition. 
1 Low serum albumin and total lymphocyte count as predictors of 30 day hospital readmission in patients

265 years of age or older

3 By Robert Robinson*

4

5 *Corresponding Author

6 Address for Correspondence

7 Robert Robinson, MD

8 Associate Professor of Clinical Medicine

9 Department of Internal Medicine

10 Southern Illinois University School of Medicine

11701 North First Street

12 PO Box 19636

13 Springfield, IL 62794-9636

14 Phone 217-545-0182

$15 \quad$ Fax 217-545-7127

16 Email rrobinson@siumed.edu

17 
18

19

\section{Introduction}

Hospital readmission within 30 days of discharge is a target for health care cost savings in the Medicare Value Based Purchasing (VBP) program through reductions in payments to hospitals with higher than expected readmission rates (Centers for Medicare and Medicaid Services, 2015). Because of the VBP initiative, health care organizations are investing considerable resources into efforts to reduce hospital readmission. Identifying patients at risk of hospital readmission can be accomplished with a variety of risk assessment tools that range from multidisciplinary patient interviews to simple screening tools using a handful of variables (Kansagara et al, 2011; Silverstein et al., 2008; Smith et al., 2000). These tools use risk factors such as age, ethnicity, socioeconomic status, severity of illness, previous hospitalizations and other factors to predict who is likely to be readmitted. Unfortunately, many risk factors for hospital readmission are not modifiable. Protein energy malnutrition (PEM) is a known and potentially modifiable risk factor for hospital readmission (Lim et al., 2012; Fontes, Generoso, and Toulson Davisson Correia, 2013; Sullivan 1992).

The prevalence of PEM in general medical inpatients is $20-45 \%$ depending on the method used to assess PEM (Bistrian et al., 1976; Williard, Gilsdorf, and Price 1980; Persson et al., 2002; Barker, Gout, and Crowe 2011). Similar rates of PEM can be found in surgical and intensive care patients (O'Daly et al., 2010; Fontes, Generoso, and Toulson Davisson Correia, 2014; Drevet et al., 2014). The subset of patients with PEM have a greater likelihood of inpatient mortality (Bonilla-Palomas et al., 2014, Persson et al., 2002, Barker, Gout, and Crowe 2011; O’Daly et al., 2010; Aziz et al., 2011; Correia and Waitzberg, 2003; Lim et al., 2012), longer length of hospital stay (Barker, Gout, and Crowe 2011; Jeejeebhoy et al.,2015; Aziz 2011; Correia and Waitzberg, 2003; Lim et al., 2012), hospital readmission (Fontes, Generoso, and Toulson Davisson Correia, 2014; Jeejeebhoy et al.,2015; Lim et al., 2012; Fontes, Generoso, and Toulson Davisson Correia, 2013; Sullivan 1992; Aziz et al., 2011; Friedmann et al., 1997), 
and inpatient costs (Correia and Waitzberg, 2003; Lim et al., 2012). Several studies have shown that inpatient nutritional interventions can improve outcomes such as mortality (Barchel et al., 2013), length of stay (Holyday et al., 2012), and hospital readmission (Holyday et al., 2012).

Unfortunately, identifying patients with PEM is complex and there is no clear consensus method of identifying patients with PEM (Kyle et al., 2006, Schneider and Hebuterne, 2000). Pablo and colleagues conducted an analysis of four commonly used nutritional assessment tools and identified the Instant Nutritional Assessment (INA) as the most sensitive and specific tool for identifying people with malnutrition at the time of hospital admission (Pablo, Izaga, and Alday 2003). The INA has a sensitivity of $100 \%$ and a specificity of $92 \%$ in this study, and relies on only two commonly obtained laboratory tests: the serum albumin level and the total lymphocyte count (Seltzer et al., 1981).

The simplicity and objectivity of the INA as a nutrition screening tool is compelling. These laboratory tests are inexpensive and are likely to be performed on the majority of patients ill enough to be admitted to a hospital. Several studies have shown good accuracy of the INA in predicting outcomes for femur fracture (Symeonidis and Clark, 2006, O’Daly et al., 2010). We hypothesize that the INA will also effectively identify medical patients at risk of hospital readmission within 30 days of discharge.

\section{Materials and Methods}

All medical patients 65 years of age or older discharged from Memorial Medical Center from January 1, 2012 to March 31, 2012 who had a determination of serum albumin level and total lymphocyte count on hospital admission were studied retrospectively. Memorial Medical Center is a 507 bed universityaffiliated tertiary care center located in Springfield, Illinois, USA. Data on gender, age, serum albumin, 
DRG weight, total lymphocyte count (TLC), and hospital readmission within 30 days was extracted from the hospital electronic medical record system in a de-identified manner.

Admission serum albumin levels and total lymphocyte counts were used to classify the nutritional status of all patients in the study. Patients with a serum albumin less than 3.5 grams/dL and/or a TLC less than 1,500 cells per mm3 were classified as having PEM. Serum albumin and TLC were examined individually and together as predictors of outcome.

Diagnosis Related Group (DRG) weight was used as a marker of severity of illness. DRG weights are defined by the Centers for Medicare and Medicaid Services on an annual basis and are related to the cost and complexity of inpatient medical care for a specific DRG.

The primary outcome investigated in this study was hospital readmission for any reason within 30 days of discharge.

Institutional review board review for this study was obtained from the Springfield Committee for

Research Involving Human Subjects. This study was determined to not meet criteria for research involving human subjects according to 45 CFR 46.101 and 45 CFR 46.102.

\section{Statistical analysis}

Serum albumin and TLC were investigated as predictors of hospital readmission within 30 days.

Qualitative variables were compared using Pearson chi $^{2}$ or Fisher's exact test and reported as frequency

(\%). Quantitative variables were compared using the non-parametric Mann-Whitney U or Kruskal-

Wallis tests and reported as mean \pm standard deviation. Rates of survival were evaluated by the 
84 included as explanatory variables in a Cox proportional-hazards regression analysis in the following

85 manner:

86

87

88

89

90

91

92

93

94

95

96

97

98

99

100

101

102

103

104
1. Age, gender, DRG weight

2. Age, gender, DRG weight, low albumin

3. Age, gender, DRG weight, low TLC

4. Age, gender, DRG weight, low albumin, low TLC

Statistical analyses were performed using SPSS version 22 (SPSS Inc., Chicago, IL, USA). Two sided $P$-values $<0.05$ were considered significant.

\section{Results}

The study population included 1,683 hospital discharges with an average age of 79 years. The majority of the patients in this sample were female (55.9\%) and had a DRG weight of $1.22(0.68)$. In this sample, 219 patients (13\%) were readmitted to the same hospital within 30 days of hospital discharge.

Protein energy malnutrition was common in this population. Low albumin was found in 973 (58\%) patients and a low TLC was found in 1,152 (68\%) patients. Low albumin and low TLC was found in 709 (42\%) of patients. Patients with PEM were older, had a higher DRG weight, and were more likely to be readmitted to the hospital within 30 days than patients without evidence of PEM (Table 1).

Kaplan-Meier analysis shows any laboratory evidence of PEM is a significant $(p<0.001)$

predictor of hospital readmission (Figure 1 and Table 2). Low serum albumin (Figure 2 and Table 3, p < 0.001) and TLC (Figure 3 and Table 4, $\mathrm{p}=0.018$ ) show similar trends. 

relationship of low albumin and low TLC to hospital readmission (Table 5). The regression model had Cstatistics ranging from 0.562 to 0.653 . The model that included age, gender, DRG weight, low albumin, and low TLC had the highest c-statistic at 0.653. Further analysis of this Cox proportional-hazards regression model showed low serum albumin (Hazard Ratio 3.27, 95\% Cl: 2.30-4.63) and higher DRG weight (Hazard Ratio 1.19, 95\% Cl: 1.03-1.38) to be significant independent predictors of hospital readmission within 30 days (Table 6).

\section{Discussion}

This study investigated the relationship of PEM to the rate of hospital readmission within 30 days of discharge in patients 65 years of age or older. These results indicate that laboratory markers of PEM can identify patients at risk of hospital readmission within 30 days of discharge. This risk determination is simple and identifies a potentially modifiable risk factor for readmission: protein energy malnutrition. hospital readmission within 30 days even when controlling for age, gender and severity of illness. The INA is moderately good at predicting hospital readmission (c-statistic 0.653 ) which is comparable to other published methods for assessing readmission risk in real time (c-statistics range from 0.53 to 0.61 , Kansagara et al, 2011). Malnutrition may not be the only cause of low serum albumin in this patient population because many illnesses can alter serum albumin values (Bachrach-Lindstrom et al., 2001; Fleck 1988). Low serum albumin level alone is predictive of longer hospital stays (Herrmann et al., 1992; Numeroso, Barilli, and Delsignore 2008; Jellinge et al., 2014), readmission (Herrmann et al., 1992) and al., 2015) in medical inpatients. 

Mini-nutritional Assessment (MNA) incorporate patient history, physical exam findings, and assessments of functional status (Dempsy and Mullen, 1987). These more complex measures of PEM are used in administer the SGA and MNA limits their widespread use. The INA, which we used in this study, was

133 shown to be superior to the SGA in a small comparative study investigating the prevalence of PEM in 134 hospitalized adults (Pablo, Izaga, and Alday, 2003) and is suitable for adaptation as an automated clinical 135 decision support tools within an electronic health record system to identify patients at increased risk of 136 hospital readmission. nature of this study. Hospital readmission data was only available from the study hospital, which could miss patients who were admitted at another hospital within 30 days of discharge. This would lead to a

140 falsely low rate of hospital readmission. Unaccounted for local care delivery variables may have a 141 significant impact on hospital readmissions within 30 days.

\section{Conclusions}

143 Protein energy malnutrition in medical inpatients is a significant predictor of hospital

144 readmission within 30 days of discharge. Further investigation focusing on comorbid conditions is 145 required to better understand the utility of laboratory tests of PEM for predicting hospital outcomes. 


\section{References}

Centers for Medicare and Medicaid Services. Hospital Value Based Purchasing. https://www.cms.gov/Medicare/Quality-Initiatives-Patient-Assessment-Instruments/hospital-valuebased-purchasing/index.html (Accessed 6/15/2015)

Lim SL, Ong KC, Chan YH, Loke WC, Ferguson M, Daniels L. Malnutrition and its impact on cost of hospitalization, length of stay, readmission and 3-year mortality. Clin Nutr. 2012 Jun;31(3):345-50. doi: 10.1016/j.clnu.2011.11.001. Epub 2011 Nov 26.

M.I. Correia, D.L. Waitzberg The impact of malnutrition on morbidity, mortality, length of hospital stay and costs evaluated through a multivariate model analysis. Clin Nutr, 22 (3) (2003), pp. 235-239

Fontes D, Generoso SD, Toulson Davisson Correia MI. Subjective global assessment: A reliable nutritional assessment tool to predict outcomes in critically ill patients. Clin Nutr. 2013 May 13. pii: S0261-5614(13)00143-X. doi: 10.1016/j.clnu.2013.05.004. [Epub ahead of print]

Holyday M, Daniells S, Bare M, Caplan GA, Petocz P, Bolin T. Malnutrition screening and early nutrition intervention in hospitalised patients in acute aged care: a randomised controlled trial. J Nutr Health Aging. 2012;16(6):562-8.

Friedmann JM, Jensen GL, Smiciklas-Wright H, McCamish MA. Predicting early nonelective hospital readmission in nutritionally compromised older adults. Am J Clin Nutr. 1997 Jun;65(6):1714-20.

Sullivan DH. Risk factors for early hospital readmission in a select population of geriatric rehabilitation patients: the significance of nutritional status. J Am Geriatr Soc. 1992 Aug;40(8):792-8.

Kansagara D, Englander H, Salanitro A, Kagen D, Theobald C, Freeman M, Kripalani S. Risk prediction models for hospital readmission: a systematic review. JAMA. 2011 Oct 19;306(15):1688-98. doi: 10.1001/jama.2011.1515.

Silverstein MD, Qin H, Mercer SQ, Fong J, Haydar Z. Risk factors for 30-day hospital readmission in patients $\geq 65$ years of age. Proc (Bayl Univ Med Cent). 2008 Oct;21(4):363-72.

Smith DM, Giobbie-Hurder A, Weinberger M, Oddone EZ, Henderson WG, Asch DA, Ashton CM, Feussner JR, Ginier P, Huey JM, Hynes DM, Loo L, Mengel CE. Predicting non-elective hospital readmissions: a multi-site study. Department of Veterans Affairs Cooperative Study Group on Primary Care and Readmissions. J Clin Epidemiol. 2000 Nov;53(11):1113-8.

Schneider SM, Hebuterne X. Use of nutritional scores to predict clinical outcomes in chronic diseases. Nutr Rev. 2000 Feb;58(2 Pt 1):31-8.

Kyle UG, Kossovsky MP, Karsegard VL, Pichard C. Comparison of tools for nutritional assessment and screening at hospital admission: a population study. Clin Nutr. 2006 Jun;25(3):409-17. Epub 2005 Dec 13. 
202

203

204

205

206

207

208

209

210

211

Pablo AM, Izaga MA, Alday LA. Assessment of nutritional status on hospital admission: nutritional scores. Eur J Clin Nutr. 2003 Jul;57(7):824-31.

Seltzer MH, Fletcher HS, Slocum BA, Engler PE. Instant nutritional assessment in the intensive care unit. JPEN J Parenter Enteral Nutr. 1981 Jan-Feb;5(1):70-2.

Herrmann FR, Safran C, Levkoff SE, Minaker KL. Serum albumin level on admission as a predictor of death, length of stay, and readmission. Arch Intern Med. 1992 Jan;152(1):125-30.

O'Daly BJ, Walsh JC, Quinlan JF, Falk GA, Stapleton R, Quinlan WR, O'Rourke SK. Serum albumin and total lymphocyte count as predictors of outcome in hip fractures. Clin Nutr. 2010 Feb;29(1):89-93. doi: 10.1016/j.clnu.2009.07.007. Epub 2009 Aug 11.

Friedmann JM, Jensen GL, Smiciklas-Wright H, McCamish MA. Predicting early nonelective hospital readmission in nutritionally compromised older adults. Am J Clin Nutr. 1997 Jun;65(6):1714-20.

Bachrach-Lindstrom M, Unosson M, Ek AC, Arnqvist HJ. Assessment of nutritional status using biochemical and anthropometric variables in a nutritional intervention study of women with hip fracture. Clin Nutr 2001;20:217-23.

Fleck A. Plasma proteins as nutritional indicators in the perioperative period. Br J Clin Pract Suppl 1988;63:20-4.

Dempsey DT, Mullen JL. Prognostic value of nutritional indices. J Parenter Enteral Nutr 1987;11:109S$14 \mathrm{~S}$.

Persson MD, Brismar KE, Katzarski KS, Nordenström J, Cederholm TE. Nutritional status using mini nutritional assessment and subjective global assessment predict mortality in geriatric patients. J Am Geriatr Soc. 2002 Dec;50(12):1996-2002.

Fontes D, Generoso Sde V, Toulson Davisson Correia MI. Subjective global assessment: a reliable nutritional assessment tool to predict outcomes in critically ill patients. Clin Nutr. 2014 Apr;33(2):291-5. doi: 10.1016/j.clnu.2013.05.004. Epub 2013 May 13.

Jeejeebhoy KN, Keller H, Gramlich L, Allard JP, Laporte M, Duerksen DR, Payette H, Bernier P, Vesnaver E, Davidson B, Teterina A, Lou W. Nutritional assessment: comparison of clinical assessment and objective variables for the prediction of length of hospital stay and readmission. Am J Clin Nutr. 2015 May;101(5):956-65. doi: 10.3945/ajcn.114.098665. Epub 2015 Mar 4.

Willard MD, Gilsdorf RB, Price RA. Protein-calorie malnutrition in a community hospital. JAMA. 1980 May 2;243(17):1720-2.

Bistrian BR, Blackburn GL, Vitale J, Cochran D, Naylor J. Prevalence of malnutrition in general medical patients. JAMA. 1976 Apr 12;235(15):1567-70. 
Barker LA, Gout BS, Crowe TC. Hospital malnutrition: prevalence, identification and impact on patients and the healthcare system. Int J Environ Res Public Health. 2011 Feb;8(2):514-27. doi: 10.3390/ijerph8020514. Epub 2011 Feb 16.

Lyons O, Whelan B, Bennett K, O'Riordan D, Silke B. Serum albumin as an outcome predictor in hospital emergency medical admissions. Eur J Intern Med. 2010 Feb;21(1):17-20. doi:

10.1016/j.ejim.2009.10.010. Epub 2009 Nov 27.

Jellinge ME, Henriksen DP, Hallas P, Brabrand M. Hypoalbuminemia is a strong predictor of 30-day allcause mortality in acutely admitted medical patients: a prospective, observational, cohort study. PLoS One. 2014 Aug 22;9(8):e105983. doi: 10.1371/journal.pone.0105983. eCollection 2014.

Barchel D, Almoznino-Sarafian D, Shteinshnaider M, Tzur I, Cohen N, Gorelik O. Clinical characteristics and prognostic significance of serum albumin changes in an internal medicine ward. Eur J Intern Med. 2013 Dec;24(8):772-8. doi: 10.1016/j.ejim.2013.08.004. Epub 2013 Sep 4.

Numeroso F, Barilli AL, Delsignore R. Prevalence and significance of hypoalbuminemia in an internal medicine department. Eur J Intern Med. 2008 Dec;19(8):587-91. doi: 10.1016/j.ejim.2007.04.029. Epub 2008 Apr 18.

Drevet S, Bioteau C, Mazière S, Couturier P, Merloz P, Tonetti J, Gavazzi G. Prevalence of protein-energy malnutrition in hospital patients over 75 years of age admitted for hip fracture. Orthop Traumatol Surg Res. 2014 Oct;100(6):669-74. doi: 10.1016/j.otsr.2014.05.003. Epub 2014 Jul 2.

Aziz EF, Javed F, Pratap B, Musat D, Nader A, Pulimi S, Alivar CL, Herzog E, Kukin ML. Malnutrition as assessed by nutritional risk index is associated with worse outcome in patients admitted with acute decompensated heart failure: an ACAP-HF data analysis. Heart Int. 2011;6(1):e2. doi: 10.4081/hi.2011.e2. Epub 2011 Jun 15.

Symeonidis PD, Clark D. Assessment of malnutrition in hip fracture patients: effects on surgical delay, hospital stay and mortality. Acta Orthop Belg. 2006 Aug;72(4):420-7. 


\section{Table $\mathbf{1}$ (on next page) \\ Patient characteristics}




\begin{tabular}{llll}
\hline & No PEM & PEM & \\
& $\mathbf{N}=\mathbf{2 6 7}$ & $\mathbf{N}=\mathbf{1 , 4 1 6}$ & \\
\hline Age in Years (SD) & $77(8.03)$ & $79(8.42)$ & $\mathrm{P}<0.001$ \\
Female Gender (\%) & $161(60 \%)$ & $780(55 \%)$ & $\mathrm{P}=0.115$ \\
DRG Weight (SD) & $1.00(0.39)$ & $1.26(0.72)$ & $\mathrm{P}<0.001$ \\
Serum Albumin g/dL (SD) & $3.82(0.23)$ & $3.12(0.61)$ & $\mathrm{P}<0.001$ \\
Total Lymphocyte Count 1,000 cells/mm3 (SD) & $3.50(14.50)$ & $1.12(1.01)$ & $\mathrm{P}<0.001$ \\
Readmitted within 30 days (\%) & $13(4.9 \%)$ & $206(14.5 \%)$ & $\mathrm{P}<0.001$ \\
\hline
\end{tabular}


Table 2 (on next page)

Comparison of 30 day readmission-free survival between patients with normal and low albumin 


\begin{tabular}{lllll}
\hline Group & Discharged & 10 Days & 20 Days & 30 Days \\
\hline Normal Albumin & 709 & 700 & 682 & 669 \\
Low Albumin & 972 & 871 & 824 & 793 \\
\hline
\end{tabular}
1 


\section{Table 3 (on next page)}

Comparison of 30 day readmission-free survival between patients with and without PEM 


\begin{tabular}{lllll}
\hline Group & Discharged & 10 Days & 20 Days & 30 Days \\
\hline No PEM & 266 & 261 & 258 & 253 \\
PEM & 1415 & 1304 & 1248 & 1209 \\
\hline
\end{tabular}
1 


\section{Table 4(on next page)}

Comparison of 30 day readmission-free survival between patients with normal and low TLC 


\begin{tabular}{lllll}
\hline Group & Discharged & 10 Days & 20 Days & 30 Days \\
\hline Normal TLC & 530 & 500 & 489 & 476 \\
Low TLC & 1151 & 1065 & 1017 & 986 \\
\hline
\end{tabular}


Table 5 (on next page)

Cox proportional-hazard regression model characteristics for hospital readmission 


\begin{tabular}{lcc}
\hline Model components & $\mathbf{- 2}$ Log Likelihood & C-statistic \\
\hline Age, gender, DRG weight & 3209.726 & 0.562 \\
Age, gender, DRG weight, low albumin & 3153.231 & 0.646 \\
Age, gender, DRG weight, low TLC & 3204.440 & 0.570 \\
\hline Age, gender, DRG weight, low albumin, low TLC & 3150.560 & 0.653 \\
\hline
\end{tabular}

1 


\section{Table 6(on next page)}

Cox proportional-hazards regression analysis of risk factors for hospital readmission 


\begin{tabular}{llllll}
\hline Variable & $\begin{array}{l}\text { Regression } \\
\text { Coefficient }\end{array}$ & $\begin{array}{l}\text { Standard } \\
\text { Error }\end{array}$ & Wald & P value & Hazard Ratio (95\% Cl) \\
\hline Age & -0.009 & 0.008 & 1.17 & 0.280 & $0.99(0.98-1.01)$ \\
Gender & -0.026 & 0.137 & 0.04 & 0.849 & $0.97(0.75-1.27)$ \\
DRG Weight & 0.177 & 0.073 & 5.85 & 0.016 & $1.19(1.03-1.38)$ \\
Low Albumin & 1.184 & 0.178 & 44.16 & $<0.001$ & $3.27(2.30-4.63)$ \\
Low TLC & 0.254 & 0.159 & 2.57 & 0.109 & $1.29(0.95-1.76)$ \\
\hline
\end{tabular}

1 
1

Kaplan-Meier plot comparing 30 day readmission rates between patients with and without PEM

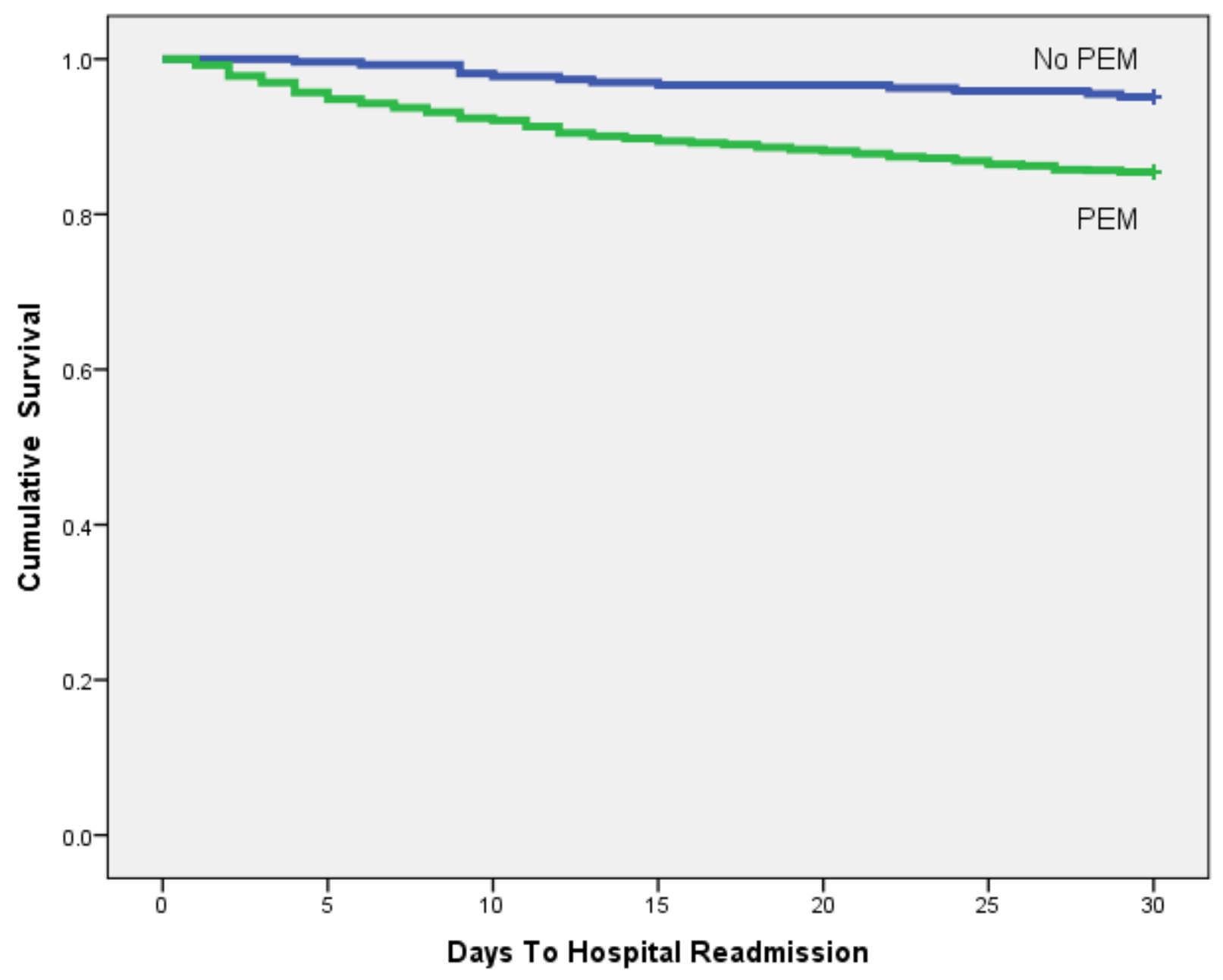


2

Kaplan-Meier plot comparing 30 day readmission rates between patients with low and normal albumin levels

Figure 2 - Kaplan-Meier plot comparing 30 day readmission rates between patients with low and normal albumin levels

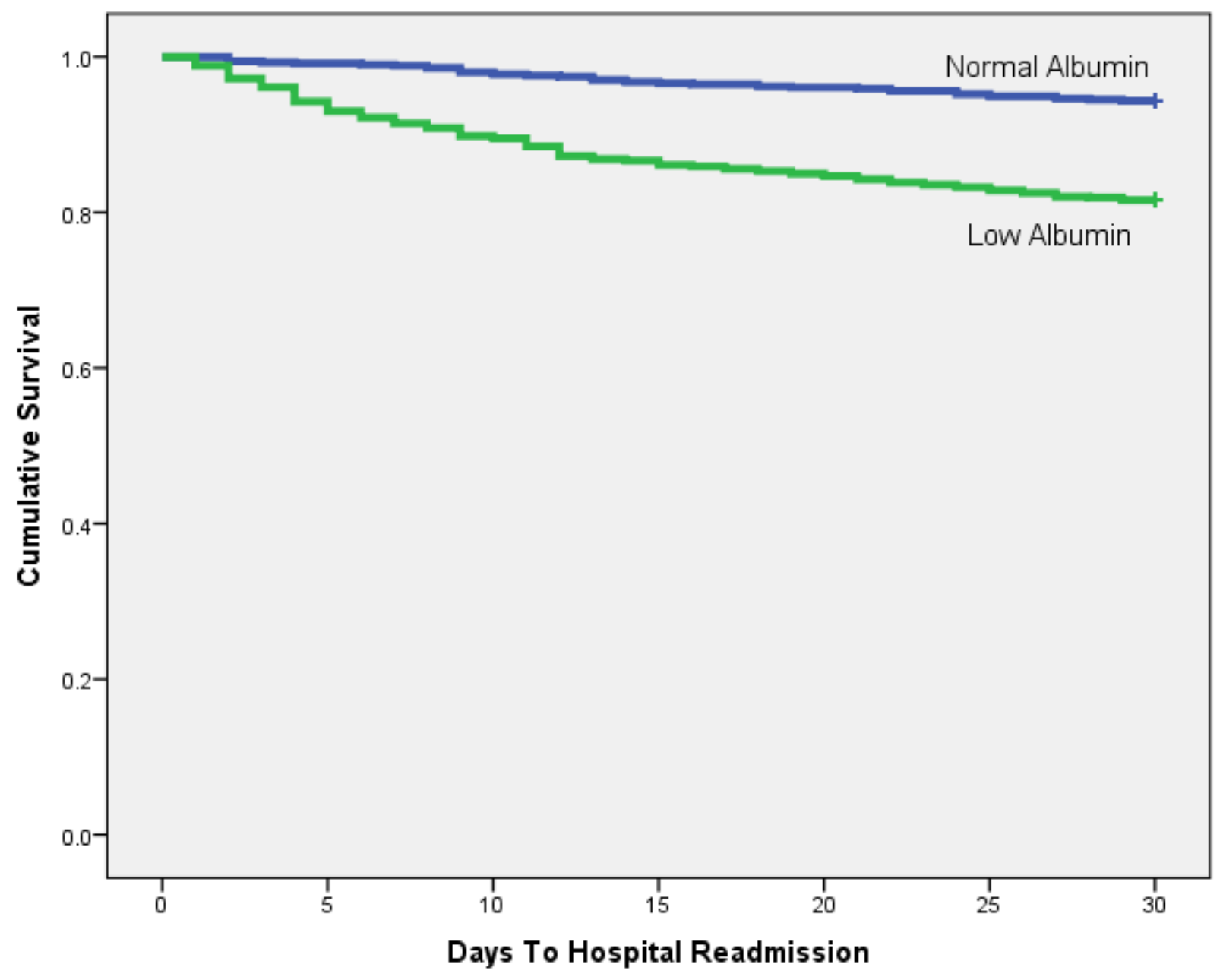


3

Kaplan-Meier plot comparing 30 day readmission rates between patients with low and normal TLC

Figure 3 - Kaplan-Meier plot comparing 30 day readmission rates between patients with low and normal TLC

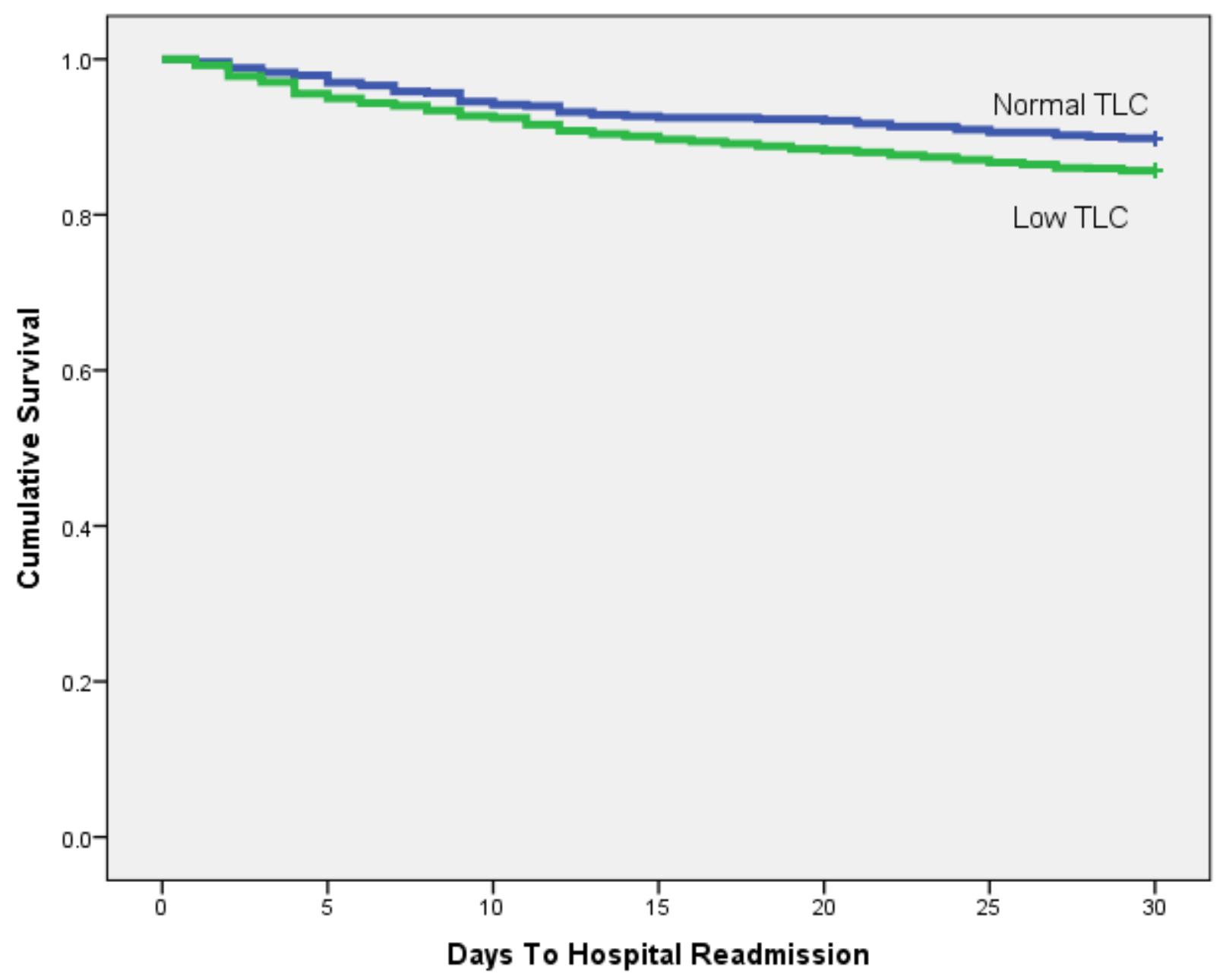

